3. Journal tops oncology journals. J Natl Cancer Inst. 1997;90:1868. News.

4. Oxman $\mathrm{AD}$, Sackett DL, Guyatt GH. Users' guide to the medical literature I. How to get started. JAMA. 1993;270:2093-5.

5. Sackett DL, Rennie D. The science of the art of the clinical examination. JAMA. 1992;267:2650-2.

6. Guarding the guardians: research on editorial peer review. Selected proceedings from the First International Congress on Peer Review in Biomedical Publications. JAMA. 1990;263:1309-456.
7. Fletcher RH, Fletcher SW. Evidence for the effectiveness of peer review. Sci Eng Ethics. 1997;3:35-50.

8. International Committee of Medical Journal Editors. Uniform requirements for manuscripts submitted to biomedical journals: editorial freedom and integrity. Ann Intern Med. 1997;126:36-47.

9. Fletcher RH, Fletcher SW. Pharmaceutical advertisements in medical journals. Ann Intern Med. 1992;116:951-2.

10. Fletcher RH, Fletcher SW. Who's responsible? Ann Intern Med. 1993; 118:645-6.

\title{
CALL FOR CLINICAL REVIEWS
}

The Editors of the Journal of General Internal Medicine remain interested in expanding the number of Clinical Reviews published in JGIM. We encourage authors and readers to submit Clinical Reviews on timely and relevant topics to the Journal. For more information on the kind of reviews we want, see our editorial “Up for Review,” J Gen Intern Med 1995;10:293-4.

Please note that our approach to Clinical Reviews has broadened. We remain interested in systematic reviews, particularly those that address a specific clinical question and are evidence-based. However, we also are interested in more synthetic and summative reviews that address broader clinical issues and concepts. We recognize that some subjects, for example, updates, are better handled using formats that depart from the systematic review and follow a more traditional outline. If you are interested in submitting a review to the Journal or have questions about our requirements for authors, please contact our editorial office at:

Philadelphia VAMC, JGIM-111

University and Woodland Avenues

Philadelphia, PA 19104

Phone: (215) 823-4471 Fax: (215) 823-4450

E-mail: jgim@mail.med.upenn.edu

We look forward to receiving your submissions. 